Volume 9 No.6, June 2020

\title{
International Journal of Advances in Computer Science and Technology
}

Available Online at http://www.warse.org/IJACST/static/pdf/file/ijacst05962020.pdf

https://doi.org/10.30534/ijacst/2020/05962020

\section{Online Placement and Recruitment System}

\author{
Akshay Venugopal ${ }^{1}$, Ashik Paily ${ }^{2}$, Balaji V Shenoi ${ }^{3}$, Bibin T Varghese ${ }^{4}$, Sreenimol K $\mathbf{R}^{5}$ \\ ${ }^{1}$ Mangalam College of Engineering, Ettumanoor, India,avenugopal24@ gmail.com \\ ${ }^{2}$ Mangalam College of Engineering, Ettumanoor, India,ashikp386@gmail.com \\ ${ }^{3}$ Mangalam College of Engineering, Ettumanoor, India, balajishenoy8@ gmail.com \\ ${ }^{4}$ Mangalam College of Engineering, Ettumanoor, India, bibinvarghese788@ gmail.com \\ ${ }^{5}$ Mangalam College of Engineering, Ettumanoor, India, sreenimol.kr@ mangalam.in
}

\begin{abstract}
The main objective of Placement Management System is to develop software which manages placement activities in college makes an interactive GUI where Placement Training Officer can manage the details of all students on his console, he can send an email to students informing about placement activities. This project mainly aims for the final year students.

Although such a project has a very wide scope, this project contains the most important part i.e. displaying the personal and academic information about a student and company. The key highlight of this project is that it is a onetime online registration enabled. The recruiters are also facilitated to verify and validate student's information. Our project provides facilities for maintaining the details of interest of the students. Students are enabled to know about the highlighted positions and skill requirements for the company. Thereby college can identify the requirements and provide required additional courses for the students. It reduces manual work and consumes less paperwork to reduce the time.
\end{abstract}

Key words: Python, My SQL, Internet, ASP

\section{INTRODUCTION}

There are many students who complete their course and only a few get jobs in what they studied. The project is aimed at developing an application for the "Online Placement and Recruitment System" of the college for final year students. The system is an application that can be accessed and can be effectively utilized all through the organization with appropriate login enabled. This allows the Placement Officers in the college to manage the student data concerning the position. With the help of this website, we would like to help all students to get recruited in companies. Usually, these processes are slow and would be difficult as they undergo any of these procedures.

The online placement management system allows the students to interact with the companies directly under the supervision of the placement coordinator. This is a simple interface and can be accessed by anyone by can be updated by the placement coordinator. The data of each student is kept protected and can be accessed by the companies, placement coordinator and the student himself. [1]

It is more convenient to access the data from anywhere and act faster, with limited options given it will be fitting with the character's needs. Also, it is important to understand that in the given limited time provided for the student, this process is faster, easier and simple to do. [7]

\section{LITERATURE REVIEW}

This system allows access and effective use of the organization using a proper login. This allows the placement officer in the college to manage information about placement. Here, students with access can add their information and can use it as a resume. One-time registration is only required. [1]

Here an ideal strategy is being used in accordance with e-recruitment with an environment friendly approach. They believe in green placement which focuses to reduce water, paper, space, time etc. by preserving the environment.[2]

Here, the author explains about the various processes and needs that must be done during a placement drive in a day to day basis. The idea is to provide various round basically around 3-5 of different, one being different from other, to reduce the number of candidates for better job allotments.[3]

It is being tested to determine which is better offline or online in a modern world. The implications for 
evaluating these media varies for different purposes. But in the fast evolving modern world and increase in new technologies to simplify the life, the online media is much better for all kind activities, it can be health, government, academic, commercial etc. with fast and easy access of data which become more difficult in offline world.[4]

We are doing this research to understand how aesthetics and design of e-commerce web pages influence the user in using these websites. In accordance with the study, aesthetic, design and simplicity of webpage providing all important amenities itself influence most of the users and user gets more attracted to these systems and they provide free advertisement to these systems.[5]

\section{TRADITIONAL SYSTEM}

Campus placement usually brings the companies to the campus which is provided by the placement coordinator for the last year students who are going to complete their graduation. Cut-off mark is requested by the company during the beginning of the open application.

Usually, companies that approach the campus come in groups of core companies. They provide broadly 3-5 sets of rounds. This is used to analyses the candidate and reduce the number of applicants to that company to ensure they get their ideal candidate. This process is called the screening process.

These rounds may include

1.Skill assessment test/Aptitude Test

2.Group discussion.

3.Technical interview

4.HR Interview [5]

These steps are arranged by the placement coordinators. These rounds may vary based on the requirements of the company. As these students are in a hurryto complete their course,they get less chance of what companies have vacancies. This limits the companies they try for placement.

This also reduces the chance for low- tier companies to offer the job. There is less time for the student as there are immersed in the works in the institution like project, seminar, exams etc., so it becomes very challenging for prepare for recruitment. [6]

\section{PROPOSED SYSTEM}

The aim of the proposed system is to develop a system with improved facilities. The proposed system can overcome all the limitations of the existing system such as, Student's information is maintained in the database, It gives more security to data, Ensures data accuracy, Reduces paperwork and saves time, Eligible students get more priority chance, Various companies can access their information etc.

The communications between is one of the key features of this idea. The pre-interaction of students with companies will help them overcome their fear during interviews. Even though competition is present the fear of completion is reduced in a virtual competition.

Even though it might take time for all to understand the system and keep up with it. By time passes users should get a better idea about it and overcome the old tradition. [8]

This implementation will be the future of the recruitment system. Practices of such will be more feasible and economical. This system uses python as front end and SQL as back end. It stores its data in a database and with the scalable property of this will make this system to be implemented on a large scale. The data will be persistent and will help to access them in just a few clicks.

The aim of this project is to develop a system with improved facilities. This allows to overcome various limitation in the existing system such as:

1. Student information maintained in the database.

2. It provides more security to the data.

3. Reduce paperwork and save time.

4. Eligible students get more priority.

5. Various companies can access this information.

6. Status of interview details can also be monitored by using the registered ID, including marks when published.

7. Notifications are sent to the student about the company's details.

8. Students get the text message and email to the registered ID and email ID.

9. Vacancy provided the companies can be viewed.

10. Companies can provide details such as salary bond, infrastructure employee, feedback, job position hierarchy etc. can be easily monitored.

11. Star rating for previously visited companies and places is possible.

\section{SYSTEM ARCHITECTURE}

This is a website which deals with placement for students into various companies. There are various essential characters in this website, and they are Admin, Placement Officer, Companies and Student. The connection between the essential characters is shown in the Fig 1. Based on different characters they have different access rights.

Admin has access over the placement officer and companies. Admin has the access right to access their 
database, add and remove anything. So, admin can know what they are doing. But admin cannot append anything in the student database.

Placement cell Manager has access right over only students of that college and can only append the student's database of that college. Managers can access information to and from the students and companies and just acts as an intermediate between the two systems. They can determine from which branch they are from.

Company has their database and contacts with the student and the placement coordinator. They are here to inform us about the vacancy and their requirements.

Student is the essential character in this system and has contact with the company only. They register themselves by entering this site. This allows the students to have open access to all about companies and their information.

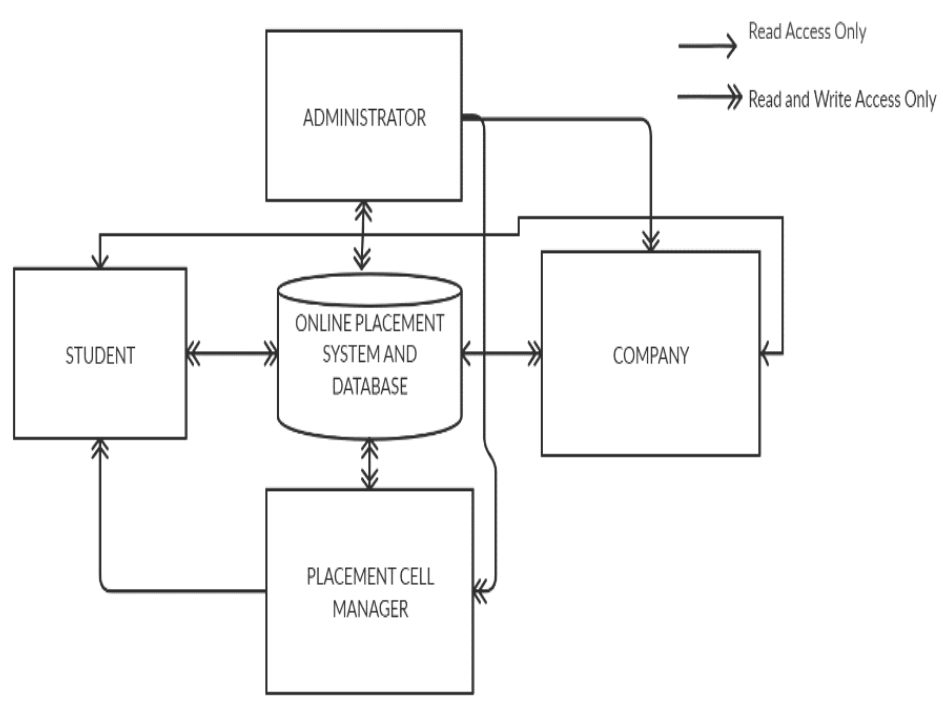

Figure1: System Architecture

\section{a.Admin}

An admin is the person who can add and remove content in the website. They can change ideas about the website and bring improvements to the website.

In this site, the major function that the admin does is managing companies and their HR managers, manage departments and their coordinator but they have only information access to view the vacancies and the students So, the data of students remains private to the admin. But admin can view placement officers and has full access to their data and manage their department and companies where admin can add or remove these data.

\section{b. Placement Officer}

In each institution, a placement officer is provided who manages the requirements of the student, manages the companies, schedules interviews, notify the student about new companies and their interview dates and their vacancies and has full access of student's data.

The officer can schedule interviews, can know students' results and who applied to the companies list, view all students selected in the final round in companies. These officers are assigned by the admin.

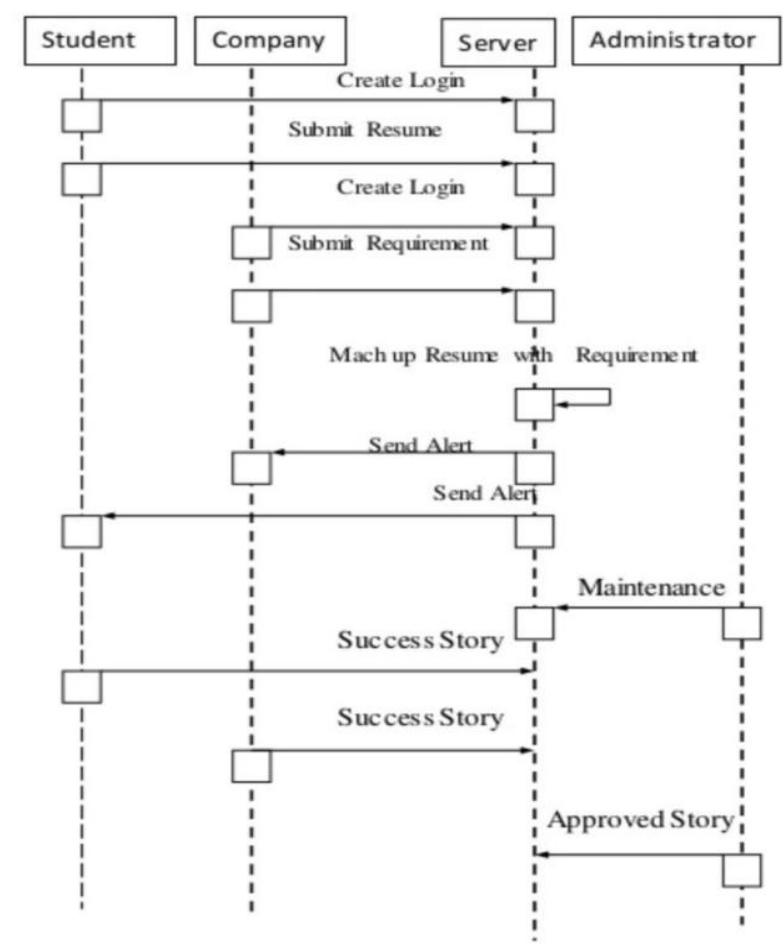

Figure 2: Sequence Diagram of the System

\section{c.Student}

Unlike others, students directly register themselves using the website registration by providing the correct information and college name and departments, to be selected, to avoid creating unnecessary databases by typing wrong names. Students have the information to see the vacancy in the company and apply for it.

They can see for what they applied for which company and see when the HR and company interview is scheduled. These are the information that the companies provide on the site. This allows the students to have direct contact with the companies. 
The processing of these things is a step by step process. All the essential characters contact through the server system. For example, a user first needs to register themselves into the site and create a login. After the person logs in, the user needs to submit his resume.

Similarly, a company can submit their requirements. After the user applies at a company, a notification is sent to the company. And companies notify students by sending that they have accepted the user's request. Maintenance is done by the admin as shown in the Figure 2. [1]

Also, it is important for software interfaces to be user friendly and provide all the amenities directly to the user. The interface should be more aesthetic and should maintain its security features. This would increase the usability of the website[12].

\section{IMPLEMENTATION}

The student needs to enter his or her information required in the registration page. The page allows the user to enter the login page of the user. This is done using python programming. The usage of HTML CSS to work register these data collected. To avoid the redundancy of the data MYSQL can be used. This allows more faster and simple access of their data.

There is a few software used in this system. They are Python used frontend as they are better in computing purposes and simple to code even being the new mode of web page development in the system and there are chances that it might improve over the courses. [9][11] This develops the webpage using the Flash.

HTML is used to design the site aesthetics and simplicity of the site using CSS. [10] MySQL is used as a database to the data stored in the site, JavaScript is linked between the front and the back end.[2][3][4].

Moreover, android systems are used to create android apps for the site for mobile access.

Hardware is an essential requirement in the development of the system in order to build the system. To do so a moderately good system is required. And software like Xammp, MySQL, Python etc., to create this site.

\section{RESULT AND CONCLUSION}

Based on the research, even though it is an upcoming system, but with proper improvements to it, this process will get popular in the future. There are lots of procedures during a placement drive, but each section takes its own time.
During this period, students face a lot of stress as they must face the all the round and at last face the interview, that for some students might be tough to overcome, and hence not getting the job. The stress of the student is an important factor during a placement drive. This stress is also a large reason for unemployment of educated students.

Big Companies, during placement drive may have to be perfect to understand about how the candidate is. This is also a task because companies undergo trial and error for selection for their post. Even Though the candidate is job efficient, the integrity of the candidate is unknown. Here, the interaction between the companies and students becomes more crucial. More they understand each other, the more the efficiency of the companies and students grows and hence the society.

The existing system works manually and there is no verification about the participants data is done. Even in the interview process the contestants must attend with hard copies of their documents, this is time consuming and energy wastage.

A future for students with busy schedules, this project may be a time saver and become more helpful for the students and the companies together.

\section{REFERENCES}

[1] Anjali V, Jeyalakshmi.PR, Anbu Bala.R ,Sri Mathura devi.G, Ranjini.V Computer Science Department, Saranathan College of Engineering, Venkateswara Nagar, Panjappur, Trichy-12, "Web Based Placement Management System”, http://ijcsit.com/docs/Volume\%207/vol7issue2 /ijcsit2016070268.pdf

[2] Gunderloy, Jorden BPB Publications (2000) - "Mastering SQL Server" San Francisco, Calif. : Sybex, 2000

[3] Luke Welling and Laura Thomson $\left(5^{\text {th }}\right.$ Edition $)$ - "PHP and MySQL Web Development" Addison-Wesley Professional

[4] Software Engineering (Theoretical Approach) Thereon Willis wrox publications (2000) - "Beginning SQL Server"

[5] Shenoy, Varun and Aithal, P. S., Green Placement - An Innovative Concept \& Strategy in Campus Placement Model 151-163. Available at

SSRN: https://ssrn.com/abstract=2849296

[6] Campus Placement: The essential steps in the process Vidhi Gaur 
Akshay Venugopal et al ., International Journal of Advances in Computer Science and Technology, 9(6), June 2020, 25 - 29

https://www.myamcat.com/blog/campus-placements-theessential-steps-in-placement-process/

[7] Gunter, B., Nicholas, D., Huntington, P., \& Williams, P.(2002).Online versus offline research: implications for evaluating digital media. Aslib Proceedings,54(4),229-239. doi:10.1108/00012530210443339

[8] Sylva, H., \& Mol, S. T. (2009). E-Recruitment: A study into applicant perceptions of an online application system. International Journal of Selection and Assessment, 17(3), 311-323. doi:10.1111/j.1468-2389.2009.00473.x

[9] Lei, K., Ma, Y., \& Tan, Z. (2014). Performance Comparison and Evaluation of Web Development Technologies in PHP, Python, and Node.js. 2014 IEEE 17th International Conference on Computational Science and Engineering. doi:10.1109/cse.2014.142

[10] Learning Web Page Design: A beginning guide to HTML, CSS, JavaScript and Web Graphics- Jennifer Robbins 5th Edition Publications "O'Reilly Media, Inc.

[11] Python Web Programming -By Steve Holden, David M Beazley Addison-Wesley Professional,5 Recensies

[12] Aesthetic design of e-commerce web pages - Webpage Complexity, Order and preference Liqiong Deng a , Marshall Scott Poole b, 1

Doi :https://doi.org/10.1016/j.elerap.2012.06.004 